\title{
Cenenstato
}

\section{Sobre história, memória e patrimônio no Sul do Brasil - monumentos aos açorianos em Porto Alegre e Florianópolis}

\author{
Eloísa Helena Capovilla da Luz Ramos \\ Doutora; Universidade do Vale do Rio dos Sinos, Membro do CEMIDI, São Leopoldo, RS, Brasil; \\ capovillaramos@gmail.com \\ Luciana da Costa de Oliveira \\ Doutora; Universidade do Vale do Rio dos Sinos, São Leopoldo, RS, Brasil; \\ luciana_de_oliveira@hotmail.com
}

Resumo: Esse texto estuda a história dos monumentos à imigração açoriana nas cidades de Porto Alegre e Florianópolis. Os e/i/migrantes açorianos ao se deslocarem para o Sul do Brasil trouxeram consigo seu modo de vida e suas crenças e aqui se organizaram social e economicamente apesar das dificuldades naturais do século XVIII. Nos séculos XIX e XX outros grupos imigrantes aqui chegaram entre os quais os alemães (1824), os italianos (1875) e os japoneses (1908). Quando estas comunidades completaram ou completam aniversário de sua chegada ao Brasil, suas lideranças, sozinhas ou juntamente com governos locais, regionais e nacionais organizaram comemorações e muitos ergueram monumentos em homenagem aos seus pioneiros, marcando definitivamente tais datas através do uso do mármore, do bronze, do cimento ou do ferro, entre outros materiais. Para a feitura desses monumentos foram buscados, além da vontade do grupo proponente, documentos, plantas, maquetes, fotografias, memórias e rememorações dos acontecimentos. Também foram lembrados os discursos pronunciados no dia da inauguração, as fotografias e os jornais, o que nos dá a dimensão de sua importância para a comunidade que os erigiu. $\mathrm{Na}$ elaboração desse texto buscamos, na história do grupo açoriano reafirmar a sua importância através dos monumentos construídos em sua homenagem e, também, questionar a atualidade desses dois lugares de memória enquanto patrimônios materiais dessas duas cidades.

Palavras-chave: História. Açorianos. Cidades. Monumentos. Patrimônio. Memória. 


\section{Introdução}

Quando visitamos os estados do Sul do Brasil percebemos a presença da imigração na formação dessa sociedade nas diversas manifestações culturais que a caracterizam e onde existem traços dessa presença em maior ou menor escala. Entre as cidades que pertencem ao recorte geográfico - Sul do Brasil - queremos destacar Porto Alegre e Florianópolis porque trazem na sua formação traços de vários grupos e/i/migrantes entre eles os açorianos, que estão entre os seus primeiros imigrantes/povoadores. Tais traços se apresentam não só na arquitetura de alguns de seus edifícios, mas, também em marcas do seu traçado urbano, na nomenclatura de seus bairros, nos monumentos à imigração e na sua gastronomia que se apresenta com sotaques, cores e sabores e/i/migrantes. Nesse texto consideramos importantes todos os aspectos elencados, mas queremos destacar, entre eles, a construção dos monumentos aos açorianos existentes nas cidades de Porto Alegre e Florianópolis. Estes monumentos são representações culturais dos açorianos e estão carregados da história e da memória dos mesmos.

Construir monumentos, neste contexto, é comemorar e é, também, prestar homenagem, já que um monumento, como nos diz o Dicionário da língua portuguesa é, em primeiro lugar, “[...] uma obra de arte levantada em honra de alguém, ou para comemorar algum acontecimento notável" (MICHAELIS, 1998, p. 1409). “A comemoração é, ainda, uma evocação de determinados acontecimentos do passado a que se atribui valor", diz Correia (2013, p. 69). Entendida como uma construção social, a comemoração torna-se clara quando em nossa escrita, dizemos o que comemoramos. Assim, ela pode ser tanto um "[...] preito em homenagem ou memória de pessoa ilustre [quanto] um fato histórico importante” (MICHAELIS, 1998, p. 541). Jelin (2002, p. 94) amplia esta percepção ao nos dizer que "as datas e os aniversários são conjunturas de ativação da memória" e Jobson Arruda assegura que as comemorações “[...] são manifestações vivas da história. Mas são, ainda, dimensões explícitas do lembrar e do esquecer” (ARRUDA, 1999, p. 43). Outro componente simbólico presente na feitura de um monumento é a gratidão aos pioneiros, aos primeiros ocupantes do espaço, aos iniciadores do processo. Um 
monumento pode ser, ainda, a re(a)presentação de um discurso ou, em última instância, um modo de "ler" uma cidade e seus habitantes. Então, estudar a presença açoriana nas cidades de Porto Alegre (capital do Estado do Rio Grande do Sul) e Florianópolis (capital do Estado de Santa Catarina), a partir de monumentos dedicados a este grupo e/i/migrante é uma forma de conhecer as raízes dos seus formadores e ainda uma maneira de reconhecer as bases sobre as quais a própria população busca assentar a sua cultura e a sua identidade.

Ítalo Calvino, nos diz sobre as cidades que:

[...] uma descrição de Zaíra como é atualmente deveria conter todo o passado de Zaíra. Mas, a cidade não conta o seu passado, ela o contém como as linhas da mão, escrito no ângulo das ruas, nas grades das janelas, nos corrimões das escadas, nas antenas dos pararaios, nos mastros das bandeiras, cada segmento riscado por arranhões, serradelas, entalhes, esfoladuras. (CALVINO, 1990, p. 14-15).

Tal como na cidade de Zaíra, os monumentos aos açorianos, representando fragmentos do passado deste grupo nas cidades de Porto Alegre e Florianópolis, nos indicam que estas duas cidades os "contém" nas camadas mais profundas de seu território, há muito tempo. É o que queremos verificar.

\section{Fragmentos da história dos açorianos no Sul do Brasil}

Os casais de açorianos que se deslocaram para a fronteira sul do Brasil a partir do ano de 1751/1752, respondendo ao Edital de Sua Majestade, de 31 de agosto de 1746 (Arquivo dos Açores, 1980, p. 377), especialmente para os atuais estados de Santa Catarina e Rio Grande do Sul, vieram em número avultado para a época (cerca de 4.000 casais) e compuseram, com outros grupos (lusobrasileiros, africanos escravizados e indígenas) que já estavam aqui, um dos principais contingentes populacionais desses territórios, assim como foram a matriz de alguns centros urbanos hoje muito importantes como os já citados Porto Alegre e Florianópolis.

Mas, ao buscarmos ressaltar a presença lusa e açoriana no Sul do Brasil no século XVIII encontramos ao mesmo tempo a disputa pela demarcação da fronteira com a coroa espanhola assinalada por quase dois séculos de guerras. 
Foi no bojo de conflitos como a Guerra Guaranítica (1754/56) que os açorianos tiveram que se adaptar e readaptar à nova vida e ao novo mundo que se lhes oferecia, pois eram parte do arsenal humano que garantiria o território para a coroa portuguesa. O deslocamento para o território brasileiro trazia então uma nova carga para este grupo porque os obrigava a se pensarem como "outros". Ao fazerem o movimento em busca da terra que lhes fora prometida em meados daquele século eles viverão, antes dos outros grupos, esta mesma experiência. Álamo de Oliveira (1994), destaca a mobilidade dos açorianos [na fronteira do Brasil Meridional], dizendo

É sempre o mar - o espaço onde o ilhéu mensura a sua própria concepção de infinito, onde desenha o seu caminho de evasão. Pelo mar, foi fazendo a sua descoberta do Mundo, partindo em verdadeira aventura desventurada, rumo ao desconhecido, quase. E em terras estranhas se foi deixando ficar aclimatando-se a outras civilizações e culturas, relevando o seu saber estar em qualquer continente. Hoje, o povo açoriano é de todos os pontos da Terra, pouco torna-viagem, arrastando sempre a concha da sua cultura. Nessas outras paragens, são notados e notáveis. (OLIVEIRA, 1994, p. 11).

O movimento de caráter e/i/migratório feito pelos açorianos foi, também, um movimento de colonização pois "o incola" que emigra torna-se colonus" (BOSI, 1992, p. 12). As palavras emigrar/imigrar/migrar estão sendo usadas aqui como partes de um mesmo movimento e têm o sentido de sair do lugar de origem e ir para outro lugar em busca de melhores condições de vida. Ao se deslocarem do seu território os açorianos vão ocupar um outro lugar que estava só no seu imaginário, e nele viver

Imigração e emigração são expressões que designam a deslocação de indivíduos do seu território geográfico, social e familiar, por um determinado tempo e inseridos numa corrente de intensidade variável, na suposição do retorno ao sítio de saída, depois de cumpridas ou não as expectativas que a motivaram, confrontandose, assim dois lugares distintos: o da saída e o de destino, ou seja, a existência de rupturas de natureza social, familiar e afectiva. (MONTEIRO, 1996, p. 20).

As populações luso-açorianas estabelecidas nestes dois espaços geográficos - Santa Catarina e Rio Grande do Sul - serão nominadas e descritas na documentação oficial como casais de número, casais d'El Rei ou ilhéus tanto 
por funcionários da Coroa Portuguesa quanto pelos lusos que já ocupavam este território no século XVIII. A distinção nominal se fez tanto pela origem suposta (das Ilhas) quanto pela sua situação de e/migrantes e não, necessariamente, pelos outros signos de que os açorianos eram portadores como o idioma e a religião, por exemplo. Coube a estes personagens, em seu desenvolvimento, ainda, semear cidades como Rio Grande, Rio Pardo (RS), São José e Itajaí (SC). A partir desse pressuposto, faz todo o sentido destacar o grupo açoriano como fundante desta região e digno de ser homenageado com um monumento.

\section{A construção da memória açoriana através dos monumentos}

Ao revisitar a história açoriana no Sul do Brasil estamos partindo da constatação de que "não há representação memorial sem traços" (CATROGA, 2001, p. 48), nem sem ritos, ou seja, acreditamos na existência de uma memória açoriana nalgumas cidades do Rio Grande do Sul e de Santa Catarina representada por traços inscritos nos seus habitantes entre os quais o modo de ver o mundo, o sotaque na fala, as crenças, as festas (Divino Espírito Santo, Santos Reis), as danças (pezinho, cana verde, chimarrita) e o preparo de alguns alimentos (açorda, catado de siri). Estes traços podem estar presentes, também, no desenho das cidades onde despontam o casario em fita, as calçadas muito estreitas, o nome do bairro - Moinhos de Vento, Azenha, Menino Deus, em Porto Alegre, Ribeirão da Ilha e Santo Antônio de Lisboa, em Florianópolis -. As ações que dão destaque à memória açoriana nestes lugares são alcançadas através de rituais de recordação, entre os quais os comemorativos, representados pela "linguagem, pelas imagens, pelas relíquias, pelos lugares, pela escrita e pelos monumentos" (CATROGA, 2001, p. 48).

Os monumentos são, portanto, parte dos rituais de re(a)presentação desses grupos nas cidades de Florianópolis e Porto Alegre, mas “são [também] um dos suportes mais nítidos e socialmente compartilhados da memória coletiva". (FREIRE, 1997, p. 45). Embora incluídos nas questões da memória pelo que encerram em seu conjunto, os monumentos são construídos/estudados, como já apontamos, em relação à gratidão, à homenagem, à comemoração e ao 
reconhecimento. Aí se inclui, também, a sua historicidade porque - mesmo que tenham sido feitos por profissionais de outros tempos e lugares - eles são equipamentos urbanos resultantes de pesquisa histórica e trazem esta marca nas suas construções. Os monumentos dedicados aos grupos imigrantes, são frutos da memória do grupo étnico que deseja construir a obra ou, de seus descendentes. Assim datas, figuras, detalhes da viagem ou da presença dos personagens, entre outros aspectos, são incorporados ao cimento, à pedra ou a outro material que seja usado. Monumentos são pensados e construídos, também, como frutos da ação política dos governos em âmbito local ou regional. É o caso dos dois monumentos aqui analisados.

No recorte proposto para esse trabalho, os monumentos serão tomados como campos de estudo a partir da história que vivenciaram nas cidades e das homenagens advindas das comemorações ocorridas nas datas simbólicas do Bicentenário da fundação da cidade de Porto Alegre e dos 250 anos do Edital de $1746^{2}$, em Florianópolis. Em ambas cidades as manifestações foram oriundas da vontade e do interesse das autoridades governamentais juntamente com as autoridades universitárias e com o respaldo das comunidades locais. Para exemplificar este tipo de interesse do poder público é exemplar o documento abaixo:

Porto Alegre, 20 de outubro de 1939

Ilmo. Sr. Presidente do IHGRS ${ }^{3}$

[...] Havendo algumas controvérsias em torno da data da fundação da cidade de Porto Alegre, e querendo esta Prefeitura assinalar com festivas comemorações a passagem do $2^{\circ}$ centenário da cidade, solicito a esclarecida colaboração deste Instituto no sentido de ser precisada esta efeméride [...] (grifos nossos).

Saúde e Fraternidade

José Loureiro da Silva, Prefeito. (IHGRS, 1975, p. 13).

O resultado da consulta deixou clara a existência de uma divergência com relação à data da fundação da cidade de Porto Alegre, antes tomada como 1740 e depois desta consulta, reformulada para 1772. Os atos comemorativos nos indicam que, ao mapear as relações do poder público em nível nacional, regional ou local, há interesses recíprocos nas homenagens que são prestadas nestas ocasiões. Ou seja, tanto os homenageados quanto os que homenageiam capitalizam benesses nestes eventos. A par destas constatações, vemos que entre 
as formas mais comuns e eficazes de homenagear os grupos e/i/migrantes e colonizadores está, como disse Freire (1997), a construção de monumentos. Eles são construídos, em geral, como meios para preservar e evocar memórias e, neste sentido, têm uma função comemorativa/rememorativa sendo criações marcadas social e historicamente.

A análise de outros monumentos à imigração construídos no Brasil, que vem sendo feita a partir da sua inclusão na lista dos lugares de memória (NORA, 1993), tem-nos mostrado que tais obras de arte, encaminhadas por diferentes autoridades (federais, estaduais, municipais) ou grupos sociais, têm sido feitas com um objetivo definido: festejar o imigrante e/ou seus descendentes. O motivo da proposição pode ser o aniversário da chegada dos pioneiros, a homenagem pelo centenário ou bicentenário, o agradecimento pela colonização do lugar. Mas pode ser, ainda, a comemoração de todas as datas. Isso gera, muitas vezes, tensão entre os grupos idealizadores desses projetos, porque os monumentos (re)apresentam a imigração e reforçam as identidades dos grupos homenageados. Nesse caso, nem sempre agradam a todos os envolvidos, pois alguns imigrantes podem ficar de fora ou outros, menos votados, serem aí incluídos.

Pari passu com o estudo dos monumentos é importante olharmos para as cidades estudadas pois "[...] ao mesmo tempo em que a imaginária organiza e caracteriza os diversos espaços urbanos, a cidade é [também] demarcada simbolicamente" (KNAUSS, 1999, p. 7) pelos mesmos. Além disso, diz Knauss, "a partir dessa intervenção [que é a construção do monumento], os cidadãos ressignificam os diversos territórios do seu cotidiano e constroem [ou reforçam] a sua identidade com a cidade" (KNAUSS, 1999, p. 7).

A construção de um monumento para os açorianos em Porto Alegre ou em Florianópolis encontrou base, como mostramos, na história do grupo açoriano no Sul do Brasil e também na reelaboração da memória da travessia oceânica no século XVIII assim como nas dificuldades para o recebimento das promessas feitas por El Rei para a fronteira sul. Apesar dos percalços, os açorianos fixaram-se na terra e ajudaram a formar os territórios catarinense e sul-rio-grandense. Neste sentido, os monumentos em homenagem a estes 
pioneiros buscaram representar, através de seu conteúdo simbólico, o patrimônio cultural de tais grupos imigrantes.

No conjunto das homenagens em ferro fundido ou cimento, que se fez aos açorianos, levou-se em conta, como já apontamos, que eles foram os primeiros imigrantes e povoadores da capital catarinense e sul-rio-grandense. No Rio Grande do Sul, na década de 1970, no contexto do centenário da imigração italiana e do sesquicentenário da imigração alemã, o Governo do Estado constituiu uma "Comissão Executiva" que deveria elaborar um programa de homenagens a todos os imigrantes no denominado "Biênio da Colonização e Imigração", que abarcava os anos de 1974 e 1975. Muitos eventos e obras foram feitos e muita documentação foi produzida e publicada no Rio Grande do Sul neste período. É no bojo deste processo que os açorianos receberam, na capital do Estado do Rio Grande do Sul, o "Monumento aos Açorianos", datado do ano de 1974 e de autoria do escultor porto-alegrense Carlos Gustavo Tenius (1939).

Figura 1 - Monumento aos Açorianos, de Carlos Gustavo Tenius. Aço corten, 17X24m, Largo dos Açorianos. Porto Alegre/RS

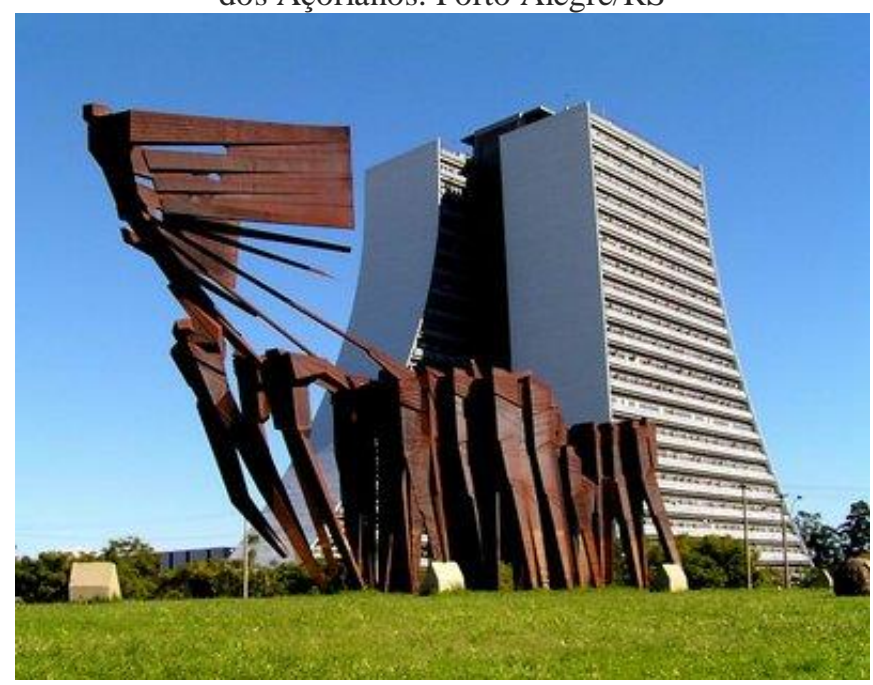

Fonte: Romulo_Lubachesky [197-?]

Já o Monumento ao Povoamento Açoriano em Florianópolis, no Estado de Santa Catarina, elaborado pelo artista Guido Heuer (1956) e erigido no ano de 1996, diferentemente do monumento de Porto Alegre, é fruto de um "consórcio internacional", celebrado entre a Universidade Federal de Santa Catarina, a Prefeitura de Florianópolis e o Governo Regional dos Açores. Os documentos consultados não nos esclarecem, mas a placa indicativa da obra diz 
que o monumento é fruto da comemoração dos 250 anos do Edital de 1746, que desencadeou o processo de e/imigração e colonização açoriana para o Sul do Brasil. Ela ocorreu entre os anos de 1750 e 1758 e contemplou principalmente o espaço litorâneo dos Estados de Santa Catarina e do Rio Grande do Sul.

Figura 02 - Monumento ao Povoamento Açoriano, Guido Heuer. Concreto, inox, metal gravado e fibra de vidro, $11 \mathrm{~m}, \mathrm{BR} 282$. Florianópolis/SC

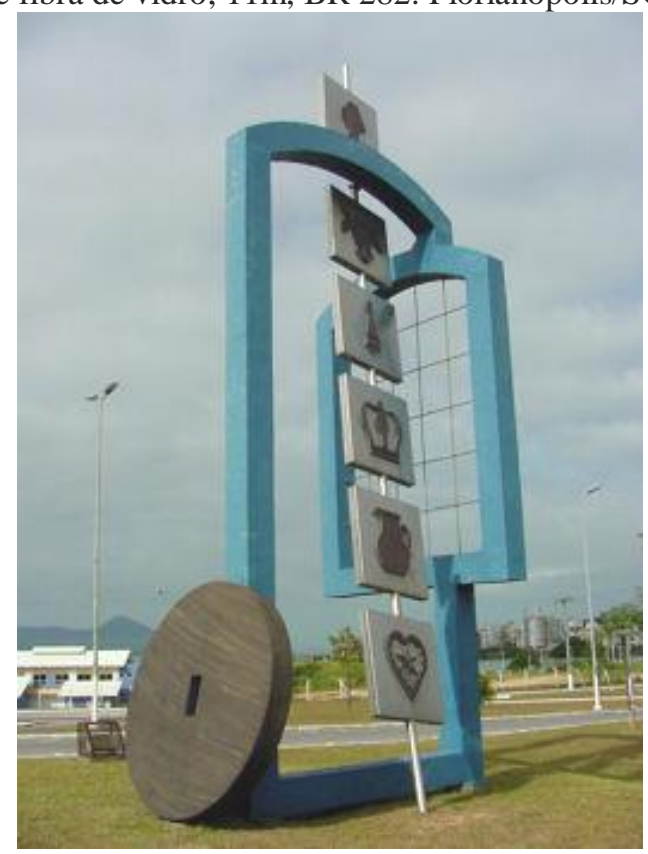

Fonte: Joi Cletison (2013).

Analisando estes dois monumentos do ponto de vista histórico, verificamos que foram construídos no final do século $\mathrm{XX}$ e que, embora separados por mais de 20 anos em sua feitura, eles têm um objetivo comum: comemorar e rememorar homenageando o grupo açoriano inicial. É um preito de gratidão e uma celebração àqueles que no passado distante vieram ocupar a “terra prometida". Os governantes, embora tenham consciência que não existem mais açorianos em suas cidades e sim descendentes da oitava ou nona geração, sabem da permanência de rastros e fragmentos do modo de vida desses sujeitos históricos. Por isto buscaram atualizar a presença açoriana em seus respectivos territórios, a partir da (re)criação de memórias, entre as quais as que são destacadas na simbologia dos monumentos e da atualização da identidade, calcada no pertencimento étnico-cultural luso-açoriano. Isto inclui ainda um jeito próprio de ver o mundo, uma religiosidade manifesta e uma cultura rica e variada, entre outros elementos. 


\section{Monumentos como patrimônios da imigração}

Aloïs Riegl ${ }^{4}$ (1903, não paginada apud CHOAY, 2001, p. 25) nos diz que "o monumento é uma criação deliberada cuja destinação foi pensada a priori, de forma imediata". Ou seja, um monumento é planejado com antecedência em sua representação, é pensado geográfica e arquitetonicamente, responde aos anseios e solicitações da comunidade e aos objetivos dos governantes ou, ainda, a ambos os preitos. Resultados de uma memória e do espírito comemorativo que carregam, os monumentos tornam-se representações da imigração açoriana nas duas cidades e, por estarem imbuídos dessa representação, vão ser tomados, também, como patrimônios da imigração.

Para que se possa compreender não apenas a materialidade de ambos os monumentos, mas, sobretudo sua significação e relevância como patrimônio histórico-cultural dos dois Estados, uma incursão acerca de seus artistas, encomendas, elaboração e espaços que ocupam se tornam de grande relevância. Nesse sentido, é importante perceber que, ao mesmo tempo em que um monumento evoca presença e memórias de idos tempos, eles igualmente se constituem como obras de arte. Sendo assim, conjuga-los como elementos artísticos e patrimoniais das regiões que os salvaguardam, ampliam a percepção de seus usos e funções bem como demarcam um lugar de memória.

A par desta constatação, nossa pesquisa mostrou que a construção do Monumento aos Açorianos em Porto Alegre/RS tentou representar a identidade desse grupo muito antes da sua feitura. Os diversos documentos consultados nos mostraram que, nos anos 1930, os urbanistas Edvaldo Pereira Paiva e Ubatuba de Farias planejaram um monumento aos 60 casais açorianos, num projeto que incluía uma nova prefeitura, um obelisco e um complexo administrativo para a cidade. Mas, esse projeto ficou no papel. Mais tarde, quando Leonel Brizola ocupou o cargo de prefeito da cidade de Porto Alegre, entre os anos 1955 a 1958, foi feito um concurso para "[...] complementar, com uma obra de arte ao ar livre a futura Praça dos Açorianos, cuja área também viria a receber um viaduto" (ALVES, 2004, p. 176). Segundo o mesmo autor, a vencedora do certame foi a artista Maria de Lourdes Sanchez Hecker, ex-aluna no Instituto de 
Artes, mas que nunca teve a obra realizada, uma vez que o processo para realização do monumento foi esquecido pelos sucessivos prefeitos da cidade. Mesmo que não tenha atingido sua finalidade, os projetos dos anos 30 e o dos anos 50 mantinham o mesmo objetivo: homenagear aos açorianos pioneiros.

Passados quase vinte anos do concurso promovido por Leonel Brizola, em 1970, a Secretaria de Obras e Viação de Porto Alegre convidou o escultor Carlos Gustavo Tenius para construir um monumento que homenageasse aos açorianos. A encomenda, por sugestão da Prefeitura Municipal, solicitava a Tenius que trabalhasse em conjunto com os escultores Vasco Prado (1914-1998) e Francisco Stockinger (1919-2009), o que não se concretizou efetivamente uma vez o que o artista “[...] apresentou, em 1973, uma pré-maquete de um trabalho de sua autoria, cuja proposta causou boa impressão e foi quase que imediatamente aceita pela prefeitura" (ALVES, 2004, p. 176).

Enquanto era preparado o protótipo do monumento, foi criada, como dissemos, a Comissão encarregada de organizar as comemorações do Biênio da Colonização e Imigração. Neste momento os dois projetos se encontraram já que a feitura do monumento aos açorianos foi incluída no projeto do Biênio. E, na "XIV Semana de Porto Alegre" do ano de 1974, o monumento foi inaugurado diante de autoridades do Município, do Estado e do Embaixador de Portugal no Brasil, José Hermano Saraiva. Em seu discurso, o Prefeito de Porto Alegre, Telmo Thompson Flores destacou que:

\footnotetext{
Dentre as solenidades de hoje, que assinalam a data da cidade, ela vem prestar a sua homenagem de extremado carinho aos pioneiros açorianos que aqui chegaram há 200 anos, para edificá-la e engrandecê-la. Este monumento, que aqui erguemos, de autoria do escultor Carlos Gustavo Tenius, relevo de arte no Parque dos Açorianos, simbolizará para todo o sempre a imorredoura gratidão dos habitantes da 'mui leal e valorosa' cidade de Porto Alegre. (CORREIO DO POVO, 1974, p. 5, grifo nosso)
}

O "Monumento ao Povoamento Açoriano" em Florianópolis/SC, teve sua construção iniciada nos anos 1990 e contou com o aporte financeiro da Prefeitura Municipal de Florianópolis. É mister que se diga, porém, que ele foi resultado de uma parceria com outras Instituições entre as quais o Governo 
Regional do Açores, que recebeu nos Açores o vencedor do concurso nacional realizado para a escolha do projeto, o escultor Guido Heuer.

O local escolhido para a construção do monumento foi a cabeceira continental da ponte Pedro Ivo Campos, sendo inaugurado em agosto de 1996. Feito de concreto, inox, metal gravado e fibra de vidro, ele se propõe homenagear o povo açoriano de aquém e de além-mar pela contribuição à história e à cultura catarinense. O local escolhido, segundo nossa percepção, é uma das áreas que se poderia chamar de histórica pois fica na região de São José, local habitado por muitos açorianos do passado e defronte à ilha de Santa Catarina e à capital, Florianópolis, que também foi ocupada pelos "homens das Ilhas". Hoje, as duas margens estão ligadas tanto pela ponte Pedro Ivo Campos quanto pela ponte Hercílio Luz.

Do ponto de vista de sua representatividade, esse monumento é constituído por uma estrutura que lembra uma janela e uma porta das casas açorianas do passado, na cor azul, tendo a seu lado uma roda de carreta, atualmente desaparecida. Os elementos que compõem o monumento, do ponto de vista formal e simbólico, apresentam diferentes aspectos que não só marcaram a vida dos açorianos na região, mas, sobretudo, os deixaram como legado para as gerações futuras. Este é o caso da roda, que simboliza a forma de transporte usada inicialmente pelos açorianos nos deslocamentos pela Ilha e pelo Continente. Além dela, o conjunto tem a atravessá-lo verticalmente uma espécie de mastro onde estão colocadas, em linha vertical, seis placas com símbolos representativos da cultura açoriana. São eles: a coroa do Espírito Santo, representando da fé do grupo no poder divino e do qual se mantêm devotos até hoje; o touro, representando a cultura das touradas que foi trazida dos Açores e, na Ilha, era representada pela "farra do boi"; o bilro, atividade feminina de "fazer renda" e que também marca a vida de muitas comunidades até o presente; o peixe, simbolizando a pesca na origem do grupo e, ainda atualmente, de grande relevo na vida litorânea de Santa Catarina; o jarro, que simboliza o trabalho com a cerâmica, em especial a cerâmica utilitária produzida tanto nos Açores quanto no Estado catarinense; o pão por Deus, representação de origem religiosa simbolizando, no monumento, as tradições orais açorianas. 
O monumento, de 11 metros de altura, nos faz observar que ele não se caracteriza pela monumentalidade, conforme se percebe pela fotografia de sua construção. Quanto à sua simbologia o monumento, em nossa percepção, se apresenta como de fácil leitura. Ou seja, pode ser compreendido por todos os que conhecem a história do lugar e do povo que ali recebeu a homenagem.

Figura 03 - Detalhe da placa no Monumento ao Povoamento Açoriano em Santa Catarina, marcando a efeméride dos 250 anos do povoamento desse grupo no Estado. Florianópolis/SC

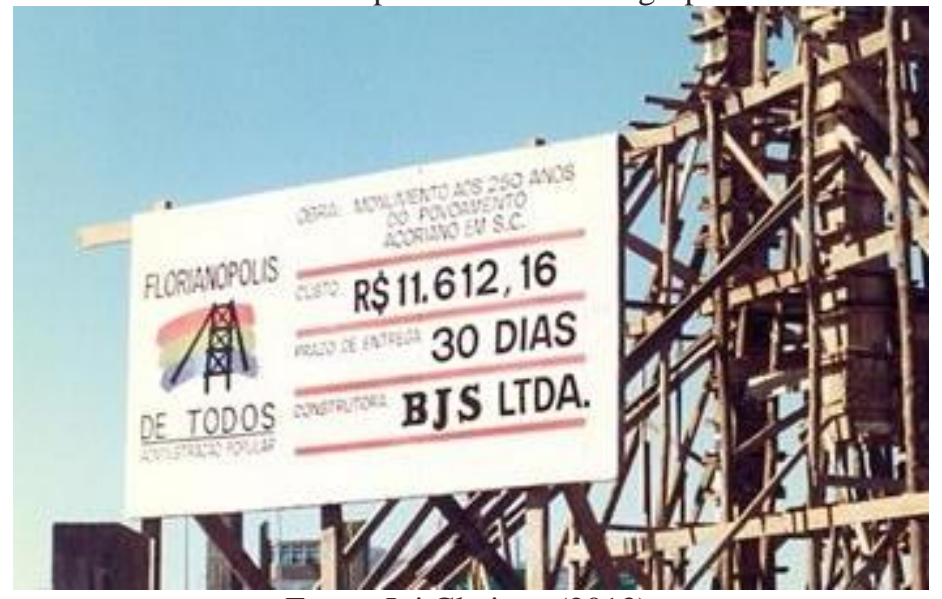

Fonte: Joi Cletison (2013).

O Monumento aos Açorianos de Porto Alegre está localizado numa área histórica: o Parque dos Açorianos, próximo à antiga ponte de pedra e ao viaduto que também homenageia estes primeiros imigrantes no sul do Brasil. Sua representatividade está dada pela sua localização e pela sua ligação com a cidade do passado. Quanto aos seus aspectos formais, a escultura é de orientação moderna. Elaborada em aço e possuindo monumentais 17 metros de altura por 24 de largura, tal obra, diferente das demais apreciadas na cidade de Porto Alegre, não possui a base assentada em mármore ou granito, mas em uma grande plataforma de concreto. A respeito de seu caráter monumental que, segundo Virgínia Araújo, “atualiza e integra a cidade ao processo de modernização do país" (ARAÚJO, 2002, p. 7).

Fernando Corona (1973), escultor consagrado e professor de Carlos Tenius durante sua formação na Escola de Artes, ao dar o parecer a respeito da obra, afirma: "Como seria um monumento a imortalizar povo tão heroico"? Respondendo seu próprio questionamento e observando a técnica de seu exaluno, Corona diz que Tenius se utilizou da 
[...] forma ciclopea dos grandes monumentos de outrora, digno de uma geração de heróis, pois assim podem ser considerados os primeiros açorianos que demarcaram a nossa cidade para os grandes destinos. (CORONA, 1973, p. 3)

Em Corona (1973) encontramos, ainda, que o monumento foi executado em aço anticorrosivo, inalterável e solda elétrica com eletrodos $O K$, também inalterável.

Em uma descrição mais interpretativa deste monumento percebemos que ele representa, simbolicamente, a travessia, o barco, o movimento, já que se compõe de um conjunto de homens sem rosto que se deslocam para o leste, sendo que alguns, tal como outrora fizera o mitológico Ícaro, alçam vôo.

Os açorianos simbolicamente nutridos de esperança elevam-se da terra na marcha heroica, libertos de opressões para os grandes destinos da terra que escolheram para engrandecê-la. (CORONA, 1973, p. 3)

Financiaram a obra, irmanadas, autoridades Estaduais e Municipais.

Figura 04 - Largo dos Açorianos.

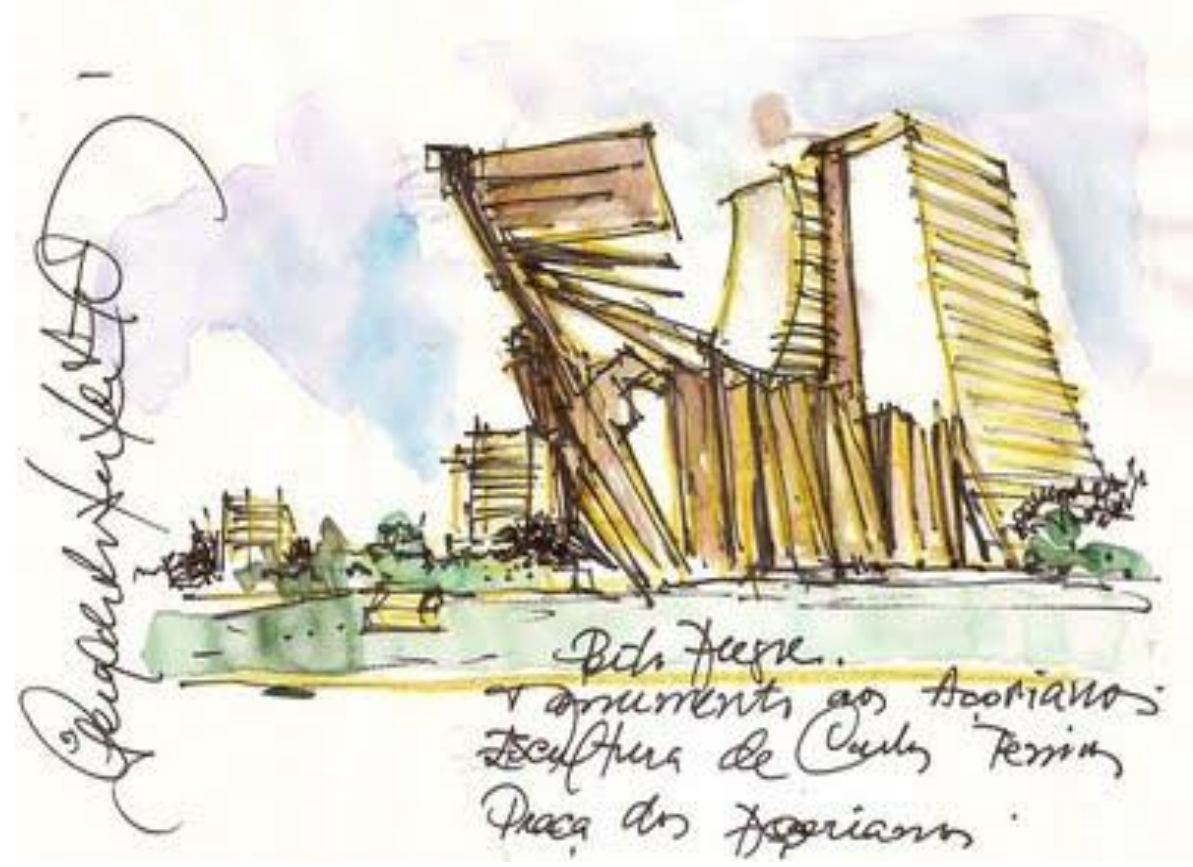

Fonte: Silva (2009). 
Figura 05 - Monumento aos Açorianos à noite, de Carlos Gustavo Tenius. Aço corten, $17 \mathrm{X}$ $24 \mathrm{~m}$.

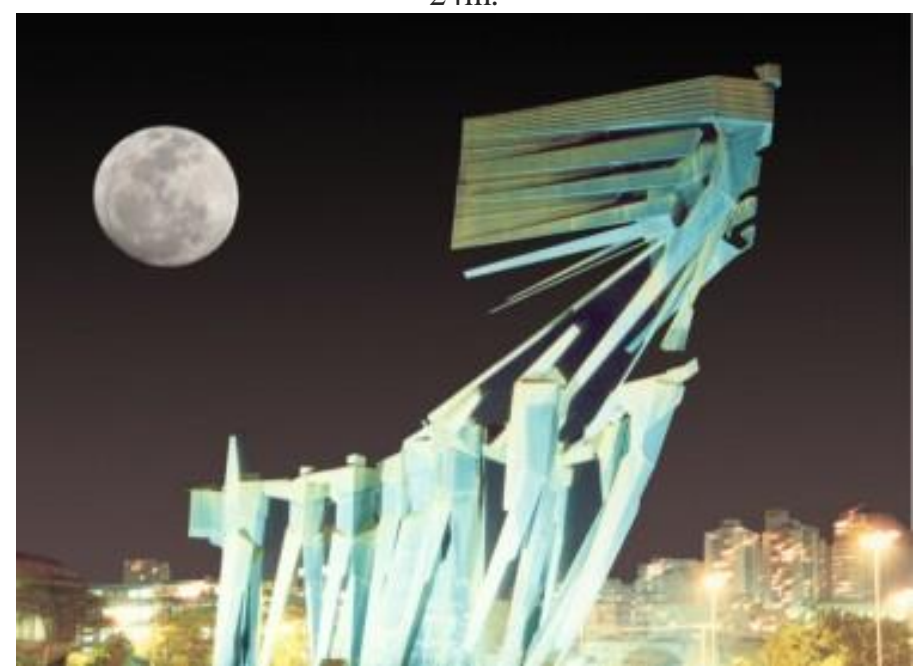

Fonte: Calazans (2014).

\section{Considerações finais}

Os monumentos aqui apresentados são, além de referências no espaço e no tempo, 'lugares de memória' dos açorianos. Mas são também representações desses grupos pela simbologia que contém. Através deles, foi possível reelaborar uma memória e destacar uma identidade açoriana nessas cidades do Sul do Brasil. Outros elementos, do passado e do presente podem ser agregados a esse estudo em homenagem aos açorianos. Nesse contexto é importante lembrar que

[...] os monumentos históricos são sempre únicos, não reproduzíveis e devem portar consigo para o futuro seus elementos caracterizadores e as marcas de sua translação no tempo, ou seja, embora sejam únicos, permitem atualizações que ocorrem ao longo do tempo, são feitas por grupos ou por indivíduos (pinturas, placas, remodelações) e oportunizam outras leituras e interpretações. (DVORÁK, 2008, p. 57)

Pensar ambos monumentos nas intercorrências do tempo, como apontou Dvorák (2008, p. 57), nos faz refletir, também, acerca das atualizações e apagamentos a que estão submetidos. Ao pensar uma obra a partir das inúmeras temporalidades e memórias que porta, conforme aponta Georges DidiHuberman (2008), é necessário problematizar, igualmente, os olhares que sobre elas recaem ao longo do tempo. Com isso, perceberemos que as percepções 
advindas no ato de sua inauguração não são as mesmas, por exemplo, das de hoje. E essa problemática é justamente a que nos leva a pensar nos sentidos que a obra adquire para cada geração e para cada gestão da administração pública.

Conforme explicitado ao longo do texto, o monumento de Porto Alegre e o de Florianópolis estão distantes no tempo. Vinte anos, aproximadamente, os separam. No entanto, as dificuldades que encontraram no ano de 2016 parece trazer á tona um problema que acomete em grande escala a arte pública nacional: o descaso, a depredação e o abandono.

O monumento de Carlos Tenius foi restaurado no ano de 2016, após intervenção do Ministério Público em $2013^{5}$ e de outras ações promovidas desde 2011. Uma delas, vale mencionar, foi o projeto Artemosfera, promovido pelo Grupo RBS, patrocinado por empresas particulares como Zaffari, Chevrolet e Braskem e apoiado pela Prefeitura Municipal de Porto Alegre e pelas Tintas Renner. Realizado no ano de 2012, o projeto tinha por objetivo realizar intervenções em obras de arte urbanas, sendo o Monumento aos Açorianos uma das contempladas. Foi o próprio Carlos Tenius quem participou da ação, batizando-a de Luzes do Mundo, recuperando o projeto original de iluminação do monumento que, desde muitos anos, já não mais existia. A respeito desse trabalho, é o próprio escultor quem sinaliza sua importância:

\footnotetext{
Reveste-se da importância em chamar a atenção à valorização histórica, de preservação e de criação em arte pública (...). Minha participação no Artemosfera tem o objetivo de incentivar e de conscientizar o município para a fundamental preservação do monumento, uma vez que se encontra com grandes focos de corrosão e sob um risco, em médio prazo, de adernamento. (ZERO HORA, 2012, não paginada)
}

Importa mencionar, ainda, que quando o artista se refere, acima, sobre os focos de corrosão, ele está apontando um dos maiores problemas enfrentados pelo monumento (e pela sociedade brasileira como um todo): ele virou ponto de abrigo para moradores de rua que, em seu interior, urinam e acendem fogueiras. Além disso, mais contemporaneamente, a Praça dos Açorianos ficou conhecida por ser um "cachorródromo", especialmente por ter sido colocado, em todo seu entorno, uma tela de proteção que, ao mesmo tempo que objetivava impedir o acesso de pessoas ao espaço, foi entendido como um lugar seguro para 
moradores das cercanias soltarem seus cachorros. Por certo, o espaço privilegiado para tais animais de estimação fazerem suas necessidades era o monumento.

Figura 06 - Corrosão na base do monumento causada pela urina humana e de animais

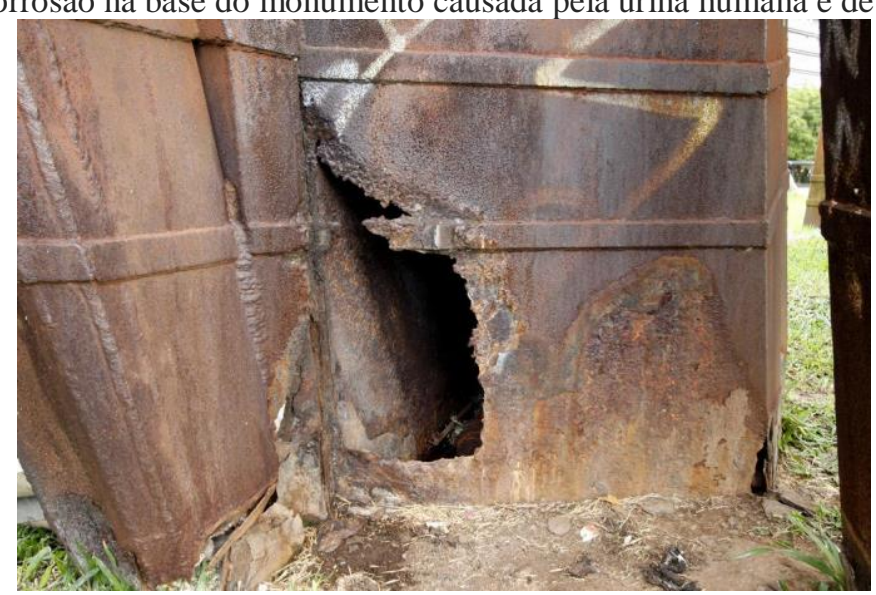

Fonte: Ministério Público RS (2010).

No mesmo ano de 2016, quando o monumento de Porto Alegre, após restauração, era devolvido à cidade, uma polêmica se estabeleceu junto ao monumento localizado na entrada da cidade de Florianópolis. No último final de semana do mês de setembro, a imprensa local veiculou uma nota em seus periódicos informando que o escultor Guido Heuer havia ficado perplexo com uma intervenção realizada no Monumento ao Povoamento Açoriano, de sua autoria. Tal intervenção estava relacionada com a pintura do monumento que, do seu original e característico azul, tornava-se, agora, rosa e branco.

A ação foi denunciada pelo Núcleo de Estudos Açorianos (NEA), da Universidade Federal de Santa Catarina (UFSC), como depredação do patrimônio público. O artista, que considerou o ato como uma "falta de respeito completa" (GADOTTI, 2016, não paginada), cobrou providências da prefeitura da cidade e, também, do responsável pelo ato delituoso: o médico e cirurgião plástico Osvaldo Pereira Filho. Ao defender-se das acusações, o médico apresentou as razões que o levaram a empreender tal ação, afirmando que o havia feito para chamar a atenção para o "descaso do poder público quanto à manutenção da obra" (GADOTTI, 2016, não paginada), colocando-se à disposição para ajudar na preservação “inclusive por intermédio da lei 
municipal que permite a adoção de monumentos" (GADOTTI, 2016, não paginada).

Figura 07 - Intervenção e mudança de cores do Monumento ao Povoamento Açoriano

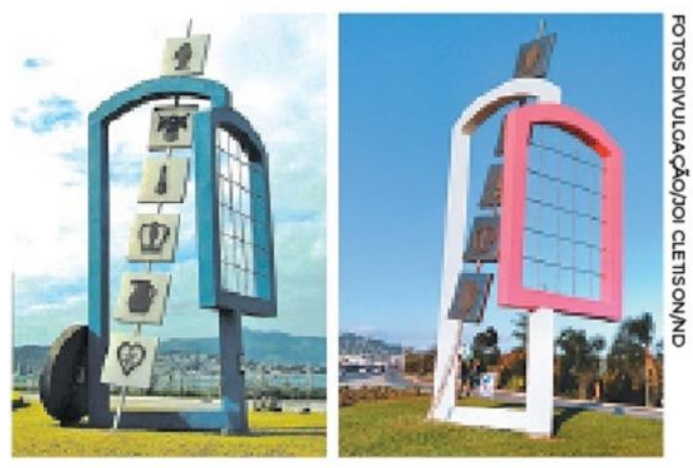

Fonte: ND+ (2016).

Pouco se sabe dos meandros do processo. No entanto, acompanhando as notícias veiculadas pela mídia, encontramos referências ao caso no ano seguinte, em 2017. Afora nos informar que o monumento recebera sua cor original após repercussão da intervenção, o jornalista Fábio Gadotti dá voz ao médico que, um tanto indignado, afirma que, naquele momento, o monumento se encontrava pior do que estava quando, então, resolveu pintá-lo de rosa e branco (GADOTTI, 2017, não paginada).

Não nos cabe aqui tomar partido na contenda. Nos cabe, no entanto, problematizar tais questões em um momento onde monumentos são contestados com os olhos do presente. Nos cabe pensar, igualmente, em suas funções originais e quais as que irá desempenhar aos olhos do futuro. Assim, dada a sua importância no espaço das cidades, os monumentos são olhados como patrimônios da imigração. As homenagens, feitas aos homens e mulheres do passado através destes patrimônios culturais permite que tenhamos, em seus desdobramentos, um outro olhar sobre esses personagens que um dia cruzaram o Atlântico em busca de uma outra terra para viver.

\section{Referências}

ALVES, José Francisco. A escultura pública de Porto Alegre. História, contexto e significados. Porto Alegre: Artfolio, 2004. 
ARAÚJO, Virgínia Gil. O cenário urbano como representação do progresso Histórias, leituras e atitudes desencadeadas pelo Monumento ao Marechal Castello Branco. Porto Alegre / 1978-1979. In: Colóquio Brasileiro de História da Arte, 22., 2002, Porto Alegre. Anais [...]. Porto Alegre: CBHA, 2002. p. 2 13.

ARQUIVO DOS AÇORES. Ponta Delgada: Universidade dos Açores. [Reedição, numa versão fac-similada, da edição do século XIX]. 1980. v. I.

ARRUDA, José Jobson de Andrade e. O trágico $5^{\circ}$ Centenário do descobrimento do Brasil: Comemorar, celebrar, refletir. São Paulo: EDUSC, 1999.

BOSI, Alfredo. Dialética da colonização. São Paulo: Companhia das Letras, 1992.

CALAZANS, Nelson Luis Vilar. Fotografia do Monumento aos Açorianos em Porto Alegre. 2014. 1 fotografia.

CALVINO, Ítalo. As cidades invisíveis. São Paulo: Companhia das Letras, 1990.

CATROGA, Fernando. Memória e história. In: PESAVENTO, Sandra J., Fronteiras do Milênio. Porto Alegre: UFRGS, 2001.

CHOAY, Françoise. A alegoria do patrimônio. São Paulo: Estação Liberdade: UNESP, 2001.

CLETISON, Joi. Detalhe da placa no Monumento ao Povoamento Açoriano em Santa Catarina, marcando a efeméride dos 250 anos do povoamento desse grupo no Estado. Florianópolis/SC. 2013. 1 fotografia.

CLETISON, Joi. Monumento ao Povoamento Açoriano, Guido Heuer. Concreto, inox, metal gravado e fibra de vidro, 11m, BR 282. Florianópolis/SC. 2013.

CORONA, Fernando. Parecer técnico do Monumento aos Açorianos de Porto Alegre-RS. IBGE: Brasil, 1973.

CORREIA, Victor. Arte Pública: seu significado e função. Lisboa: Fonte da Palavra, 2013.

CORREIO DO POVO. Porto Alegre, 27 de março de 1973. p. 5.

DIDI-HUBERMAN, Georges. Antes el tempo. Historia del arte y anacronismo de las imágenes. Buenos Aires: Adriana Hidalgo, 2008. 
DVORÁK, Max. Catecismo da preservação de monumentos. Cotia: Ateliê, 2008.

EMIGRAR. In: MICHAELIS moderno dicionário da língua portuguesa. São Paulo: Melhoramentos, 1998.

FREIRE, Cristina. Além dos mapas. São Paulo: Sesc/Annablume, 1997.

GADOTTI, Fábio. Guido Heuer diz que ficou "perplexo" com a mudança de cor do monumento. ND+, Florianópolis, 20 set. 2016.

GADOTTI, Fábio. Um ano depois de polêmica, monumento açoriano de Florianópolis continua abandonado. ND+, Florianópolis, 16 out. 2017.

IMIGRAR. In: MICHAELIS moderno dicionário da língua portuguesa. São Paulo: Melhoramentos, 1998.

JELIN, Elisabeth. Los trabajos de la memoria. Madrid: Siglo XXI, 2002.

KNAUSS, Paulo. Cidade vaidosa: imagens urbanas do Rio de Janeiro. Rio de Janeiro: Sette Letras, 1999.

LUBACHESKY, Romulo. Monumento aos Açorianos, de Carlos Gustavo Tenius. Aço corten, 17X24m, Largo dos Açorianos. Porto Alegre/RS. [197?]. 1 fotografia.

MINISTÉRIO PÚBLICO RS. Inquérito civil apura deterioração do Monumento aos Açorianos. 02 jun. 2010.

MONTEIRO, Miguel. Migrantes e emigrantes de Fafe (1834-1926)

territórios, estrutura social e itinerários - 1. ${ }^{\mathrm{a}} \mathrm{s}$ jornadas de História local. Fafe: Câmara Municipal de Fafe, 1996.

MONUMENTO. In: MICHAELIS moderno dicionário da língua portuguesa. São Paulo: Melhoramentos, 1998.

NORA, Pierre. Entre memória e história: a problemática dos lugares. In: Projeto História. Revista do Programa de Estudos Pós-Graduados de História, São Paulo, n. 10, 1993.

OLIVEIRA, Álamo de. Já não gosto de chocolates. Ponta Delgada: Companhia das Ilhas, 2014.

REVISTA DO INSTITUTO HISTÓRICO E GEOGRÁFICO DO RIO GRANDE DO SUL. Porto Alegre: IHGRS, n. 121, 1975.

SILVA, Geraldo Roberto da. Largo dos Açorianos. 2009. 1 fotografia. 
ZERO HORA. Carlos Tenius resgata iluminação do Monumento aos Açorianos. 18 jan. 2012.

\title{
About history, memory and heritage in southern Brazil - monuments to Azoreans in Porto Alegre and Florianópolis
}

\begin{abstract}
This text studies the history of monuments to Azorean immigration in the cities of Porto Alegre and Florianópolis. The Azorean im/migrants, when moving to South Brazil, brought with them their way of life and their beliefs and here they organized themselves socially and economically, despite the natural difficulties of the 18th century. In the 19th and 20th centuries other immigrant groups arrived here, among them the Germans (1824), the Italians (1875) and the Japanese (1908). In the occasion of these communities' arrival anniversaries in Brazil, their leaders - alone or together with local, regional and national governments - organized celebrations and many erected monuments in honor of their pioneers, marking, definitively, such dates through the use of marble, bronze, cement or iron, among other materials. In order to build these monuments, besides the wishes of the proposing group, documents, plans, models, photographs, memories and recalls of events were sought after. The speeches delivered on the inauguration day were also remembered, along with photographs and newspapers, which gives us the dimension of their importance for the community that built them. During the elaboration of this text, we sought, in the history of the Azorean group, to reaffirm its importance through the monuments built in their honor and also to question the actuality of these two places of memory as material heritage of these two cities.
\end{abstract}

Keywords: History. Azoreans. Cities. Monuments. Heritage. Memory.

Recebido: $13 / 08 / 2020$

Aceito: $11 / 09 / 2020$

\section{Declaração de autoria}

Concepção e elaboração do estudo: Eloísa Helena Capovilla da Luz Ramos, Luciana da Costa de Oliveira

Coleta de dados: Eloísa Helena Capovilla da Luz Ramos, Luciana da Costa de Oliveira

Análise e discussão de dados: Eloísa Helena Capovilla da Luz Ramos, Luciana da Costa de Oliveira

Redação e revisão do manuscrito: Eloísa Helena Capovilla da Luz Ramos, Luciana da Costa de Oliveira 


\section{Como citar}

RAMOS, Heloísa Helena Capovilla da Luz; OLIVEIRA, Luciana da Costa de. Sobre história, memória e patrimônio no Sul do Brasil - monumentos aos açorianos em Porto Alegre e Florianópolis. Em Questão, Porto Alegre, v. 26, p. 121-142, Edição Especial Dossiê Patrimônio e Culturas Tradicionais, 2020. Doi: http://dx.doi.org/10.19132/1808-5245260.121-142

\footnotetext{
${ }^{1}$ Palavra de origem latina que pode ser traduzida como o que habita. Já colonus é o que cultiva o solo.

${ }^{2}$ Registro do Edital que S.M. mandou imprimir para os moradores das Ilhas do Açores e casais e todas as mais que se quisesse[m] alistar por povoadores deste estabelecimento e Santa Catarina [31 de agosto de 1746].

${ }^{3}$ IHGRS - Instituto Histórico e Geográfico do Rio Grande do Sul. A Revista de n. 121, de 1975, do IHGRS foi toda dedicada ao estudo da fundação de Porto Alegre e se constitui num documento valioso para o conhecimento da história da cidade.

${ }^{4}$ RIEGL, Alois, Le Culte moderne des monuments. Paris: Le Seuil, 1984. Apud CHOAY (2001).

${ }^{5}$ A obra foi realizada pela Secretaria Municipal do Meio Ambiente (SMAM) com orientação técnica da Coordenação da Memória Cultural da Secretaria Municipal de Cultura de Porto Alegre.
} 